\title{
Elaboração e caracterização de fermentado alcoólico de jabuticaba (Plinia
}

\section{jaboticaba) produzido artesanalmente}

\author{
Elaboration and characterization of jabuticaba alcoholic fermented (Plinia jaboticaba) handcrafted \\ Elaboración y caracterización de fermentado alcohólico de jabuticaba (Plinia jaboticaba) producido
} artesanalmente

Recebido: 11/03/2021 | Revisado: 18/03/2021 | Aceito: 22/03/2021 | Publicado: 29/03/2021

Nathalia de Andrade Neves
ORCID: https://orcid.org/0000-0001-6936-2171
Universidade Federal dos Vales do Jequitinhonha e Mucuri, Brasil
E-mail: nathalia.neves@ufvjm.edu.br
Paulo César Stringheta
ORCID: https://orcid.org/0000-0002-1229-7038
Universidade Federal de Viçosa, Brasil
E-mail:p.stringheta@ufv.br
Esteban García-Romero
Instituto Regional de Investigación y Desarrollo Agroalimentario y Forestal de Castilla-La Mancha, Espanha
E-mail: estebang@jccm.es
Sérgio Gómez-Alonso
ORCID: https://orcid.org/0000-0002-2358-6636
Universidad de Castilla-La Mancha, Espanha
E-mail: sergio.gomez@ uclm.es

\begin{abstract}
Resumo
A jabuticaba (Plinia jaboticaba (DC) Berg.) é considerada uma das principais fontes brasileiras de antocianinas. Muita apreciada, seu consumo ocorre nas formas in natura e a partir da elaboração de produtos processados, tais como geleias, doces, licores e fermentados alcoólicos. Embora popular, o fermentado alcoólico de jabuticaba é produzido de maneira artesanal, com pouco controle de qualidade e falta de padronização. O presente trabalho teve por objetivo caracterizar quimicamente o fermentado de jabuticaba produzido de maneira artesanal, sendo avaliado o $\mathrm{pH}$, teor de compostos fenólicos, antocianinas totais, monoméricas e polimerizadas, açúcares, etanol, taninos totais, capacidade antioxidante, intensidade de cor, tonalidade e composição da cor, teor de ácido elágico, ácidos orgânicos, 2,3,-butanodiol, glicerina, aminoácidos, aminas biogênicas e íon amônia. A partir dos resultados, foi possível fazer a caracterização das bebidas, com destaque para a concentração de ácido elágico, que foi acima do normalmente encontrado em vinhos tradicionais. A concentração de ácido lático e aminas biogênicas atestam indiretamente a qualidade sanitária da bebida, parâmetro importante em se tratando de bebidas artesanais. Espera-se com esse trabalho contribuir com a possibilidade da construção de um padrão de qualidade para esse tipo de bebida.
\end{abstract}

Palavras-chave: Myrciaria cauliflora; "Vinho" de jabuticaba; Ácido elágico; Jabuticaba sabará.

\begin{abstract}
Jabuticaba (Plinia jaboticaba (DC) Berg.) is considered one of the most important Brazilian sources of anthocyanins. Very appreciated, its consumption occurs in the fresh forms and as a processed product, such as jellies, liquors and alcoholic fermented beverages. Although popular, the alcoholic fermented is produced as artisanal way, with poor quality control and no standardization. The objective of this work was to characterize chemically the fermented beverage from jabuticaba produced in an artisanal way, being evaluated the $\mathrm{pH}$, content of phenolic compounds, total, monomeric and polymerized anthocyanins, sugars, ethanol, total tannins, antioxidant capacity, color intensity, hue and color composition, ellagic acid content, organic acids, 2,3, -butanediol, glycerin, amino acids, biogenic amines and ammonia ion. From the results, it was possible to characterize the beverages, with emphasis on the concentration of ellagic acid, which was above that normally found in traditional wines. The concentration of lactic acid and biogenic amines indirectly attest to the sanitary quality of the product, an important parameter when it comes to artisanal beverages. With this work is expected to contribute to the possibility of building a quality standard for this type of product.
\end{abstract}

Keywords: Myrciaria cauliflora; "Jabuticaba wine”; Ellagic acid; Jabuticaba sabará. 


\begin{abstract}
Resumen
Jabuticaba (Plinia jaboticaba (DC) Berg.) es considerada una de las principales fuentes brasileñas de antocianinas. Muy apreciada, su consumo se da in natura y a partir de la elaboración de productos procesados, como gelatinas, dulces, licores y fermentados alcohólicos. Aunque popular, la bebida alcohólica fermentada de jabuticaba se produce de forma artesanal, con poco control de calidad y falta de estandarización. El objetivo de este trabajo fue caracterizar químicamente la bebida alcohólica fermentada de jabuticaba producida de forma artesanal, evaluándose el $\mathrm{pH}$, contenido de compuestos fenólicos, antocianinas totales, monoméricas y polimerizadas, azúcares, etanol, taninos totales, capacidad antioxidante, intensidad de color, tonalidad y composición de color, contenido de ácido elágico, ácidos orgánicos, 2,3, -butanodiol, glicerina, aminoácidos, aminas biogénicas y ion amoniaco. A partir de los resultados, fue posible caracterizar las bebidas, con énfasis en la concentración de ácido elágico, que fue superior a la que se encuentra normalmente en los vinos tradicionales. La concentración de ácido láctico y aminas biogénicas atestigua indirectamente la calidad sanitaria de la bebida, un parámetro importante cuando se trata de bebidas artesanales. Se espera que este trabajo contribuya a la posibilidad de construir un estándar de calidad para este tipo de bebida.
\end{abstract}

Palabras clave: Myrciaria cauliflora; "Vino" de jabuticaba; Ácido elágico; Jabuticaba sabará.

\title{
1. Introdução
}

A jabuticaba (Plinia jaboticaba (DC) Berg.) é uma fruta não climatérica, caracterizada como uma baga esférica e suculenta. Possui cascas negras finas e frágeis, polpa branca levemente ácida e doce (Gurak, De Bona, Tessaro, \& Marczak, 2014). É reconhecida como uma das principais fontes tipicamente brasileiras de antocianinas, além de possuir grande quantidade de taninos e outros compostos fenólicos (Wu, Long, \& Kennelly, 2013).

Atualmente seu consumo é muito restrito, sendo este preferencialmente in natura e somente na época da safra, que ocorre uma vez ao ano e tem curta duração (Leite-Legatti et al., 2012). Ademais, no consumo in natura, somente a polpa é aproveitada. As cascas, onde estão concentradas a maior parte da composição fenólica, são normalmente descartadas (Santiago et al., 2021). No entanto, estudos apontam um grande potencial do fruto para o processamento industrial, como na fabricação de sucos, compotas, licores, fermentados alcoólicos, geleias, dentre outros (Gurak et al., 2014), sendo essa uma forma de diversificar o consumo e estendê-lo para além da safra. Produtos típicos elaborados a partir da jabuticaba podem ser encontrados em festas tradicionais ou caracterizados como produtos regionais, sendo eles muito apreciados entre os consumidores (Neves, Fernandes, Valente, Barros, \& Stringheta, 2020). Dentre os produtos tipicamente produzidos a partir da jabuticaba, pode-se citar o fermentado alcoólico.

Segundo o decreto $\mathrm{n}^{\circ} 6871$ de 04 de junho de 2009, "Fermentado de fruta é a bebida com graduação alcoólica de quatro a quatorze por cento em volume, a vinte graus Celsius, obtida pela fermentação alcoólica do mosto de fruta sã, fresca e madura de uma única espécie, do respectivo suco integral ou concentrado, ou polpa, que poderá nestes casos, ser adicionado de água" (Brasil, 2009).

Embora populares, os fermentados alcoólicos de jabuticaba são produzidos de maneira artesanal, estando restritos ao mercado consumidor regional, onde possuem grande aceitação. A forma artesanal de produção também resulta em baixo controle de qualidade e na falta de padronização do produto. Na maioria das vezes os produtores desconhecem as técnicas de obtenção das bebidas, negligenciando etapas e não aproveitando o potencial da composição fenólica e sabor dos frutos na obtenção de bebidas de qualidade.

Por se tratar de um mercado informal e pelo emprego de tecnologias muitos simples, os fermentados de jabuticaba são muito pouco estudados. Ao passo que conhecimento acerca de sua composição pode contribuir para a melhoria da sua qualidade e aperfeiçoamento das técnicas de obtenção, favorecendo o seu reconhecimento como uma bebida típica e de qualidade. Dessa forma, o presente trabalho teve por objetivo a produção de fermentados alcoólicos de jabuticaba, de maneira artesanal e a sua caracterização físico-química. 


\section{Material e Métodos}

\section{Aquisição dos frutos}

Os frutos de jabuticaba, da espécie sabará, (Plinia jaboticaba) foram colhidos em novembro de 2013 no pomar do Setor de Fruticultura do Departamento de Fitotecnia da Universidade Federal de Viçosa- Minas, Gerais. Os frutos foram selecionados quanto ao grau de maturação e injúrias, submetidos à higienização por água corrente e embalados em sacos plásticos em porções de $1 \mathrm{~kg}$. Estes foram mantidos congelados em ultra freezer (-80 C) até o momento do processamento.

\section{Elaboração dos fermentados alcoólicos}

A elaboração dos fermentados alcoólicos de jabuticaba ocorreu por meio do processo de fermentação em recipientes de vidro com capacidade nominal de $5 \mathrm{~L}$. Seguindo formulação elaborada a partir de testes preliminares, foram adicionados ao recipiente $1 \mathrm{~kg}$ de jabuticaba esmagadas manualmente, 1,5 L de água mineral, 1,0 L de xarope contendo $700 \mathrm{~g}$ de sacarose $\mathrm{e}$ 0,5 L de uma suspensão contendo $10 \mathrm{~g}$ de leveduras liofilizadas (Saccharomyces cerevisae) da marca comercial Fleschmann. Após 72 horas do início do processo fermentativo, foi realizada a descuba, na qual as cascas e sementes de jabuticaba foram retirados do mosto de fermentação. Após o fim da fermentação, quando era observado o depósito de leveduras no fundo do recipiente, o fim da formação de bolhas de $\mathrm{CO}_{2}$ e a estabilização do teor de sólidos solúveis totais ( ${ }^{\circ} \mathrm{Brix}$ ), foi realizado o processo de trasfega, obtendo-se assim bebidas límpidas. $\mathrm{O}$ fermentado foi mantido sob refrigeração $\left(4{ }^{\circ} \mathrm{C} \pm 1\right)$ por 7 dias, seguidos de uma segunda trasfega e envasamento em garrafas de vidro, de cor âmbar, com capacidade para 3,5 L. No momento do envase, foram adicionados $0,05 \mathrm{~g} / \mathrm{L}$ de metabissulfito de potássio com finalidade conservante. $\mathrm{O}$ fermentado foi elaborado em triplicata.

\section{Caracterização da bebida}

\section{Análises espectrofotométricas}

O fermentado alcoólico obtido foi caracterizado quanto ao $\mathrm{pH}$ (OIV-International Organization of Vine and Wine, 2013), compostos fenólicos totais, pelo método de Folin-Ciocalteu (Ough \& Amerine, 1988), antocianinas totais e polimerizadas, pelo método de descoloração por dióxido de enxofre (Ribéreau-Gayon \& Stonestreet, 1965), açúcares (OIV, 2013), teor alcoólico, por densitometria (Embrapa, 2010), taninos totais, pelo método de reação com ácido clorídrico (Glories, 1984), capacidade antioxidante pelo método da capacidade de captura de radicais DPPH (2,2 difenil-1-picril-hidrazil) (BrandWilliams, Cuvelier, \& Berset, 1995), intensidade de cor, tonalidade e composição de cor (Ribéreau-Gayon, Glories, Maujean, $\&$ Duboudieu, 2002).

Todos os resultados foram expressos por meio de média \pm desvio padrão da triplicata.

\section{Análise das antocianinas monoméricas e ácido elágico por HPLC-DAD-ESI MSN}

A separação, identificação e quantificação do teor de antocianinas e ácido elágico por HPLC foram executadas pelo sistema Agilent 1100 Series (Agilent-Alemanha) equipado com um sistema de detecção UV-Vis tipo arranjo de diodo (DAD, G1315B) e um detector de espectroscopia de massa tipo armadilha de íons (LC/MSD Trap VL, G2445C VL) com sistema de ionização por eletrospray (sistema HPLC-DAD-ES-MSn). O sistema HPLC e o DAD estavam acoplados ao processador de dados Agilent ChemStation (versão B.01.03). Os dados de espectroscopia de massas foram processados pelo software Agilent LC/MS versão 5.3.

Para a análise de antocianinas, foram utilizados $20 \mu \mathrm{L}$ da bebida diluída em $\mathrm{HCl} 0,1 \mathrm{~N}(1: 1)$, injetadas em uma coluna de fase reversa (Zorbax Eclipse XDB-C18 - 2,1 X150 mm; 3,5 $\mu \mathrm{m}$, Agilent) termostatizada a $40{ }^{\circ} \mathrm{C}$, com um fluxo da fase móvel de $0,19 \mathrm{~mL} / \mathrm{min}$. O solvente A foi composto por acetonitrila/água/ácido fórmico $(3 / 88,5 / 8,5, \mathrm{v} / \mathrm{v} / \mathrm{v})$ e o solvente B por 
acetonitrila/água/ácido fórmico (50/41,5/8,5, v/v/v). O seguinte gradiente de eluição foi utilizado: zero min (97\% A e 3\% B), $20 \min (72 \%$ A e $28 \%$ B), $34 \min (57 \%$ A e $43 \%$ B), $36 \min (100 \%$ B), $42 \min (100 \%$ B), $45 \min (97 \%$ A e 3\% B). Para a identificação o sistema ESI/MS-MS foi operado no modo positivo ionização. Os parâmetros utilizados foram: gás de secagem (N2) com fluxo de $8 \mathrm{~L} / \mathrm{min}$ e temperatura de secagem de $325{ }^{\circ} \mathrm{C}$ e nebulização $\mathrm{N} 2$ a 50 psi. Os parâmetros de ionização e fragmentação foram otimizados pela injeção direta de soluções-padrão de malvidina 3-glicosídeo, utilizando um intervalo de escaneamento de 50-1200 m/z. A identificação foi baseada nos dados espectroscópicos (UV-Vis e MS/MS) obtidos por padrões autênticos previamente descritos e reportados (Inada et al., 2015; Rebello et al., 2013). Para a quantificação foram utilizadas as áreas dos gráficos dos cromatogramas (DAD) obtidos a $520 \mathrm{~nm}$.

Para a análise do ácido elágico, foram evaporados $3 \mathrm{~mL}$ dos fermentados e redissolvidos em $2 \mathrm{~mL}$ de ácido acético 2,5\% (v/v). As amostras obtidas foram então passadas por cartucho de Sephadex LH-20 (capacidade de 6 mL) (Sigma Aldrich, San Luis, MO, USA), que foram preenchidos até $3 \mathrm{~cm}$ de altura com uma suspensão da resina em metanol, preparada várias horas antes. As colunas foram condicionadas com $4 \mathrm{~mL}$ de metanol seguidos por $4 \mathrm{~mL}$ de água. Após a passagem das amostras, as colunas foram lavadas com $2 \mathrm{~mL}$ de água, $2 \mathrm{~mL}$ de etanol $96 \%$ (v/v) e1 mL de metanol. Foram passados então 10 $\mathrm{mL}$ de metanol seguidos de $10 \mathrm{~mL}$ de acetato de etila, que foram recolhidos em balão e levados à evaporação em rota-vapor. Após a evaporação, a fração foi redissolvida em $1,5 \mathrm{~mL}$ da solução de ácido fórmico $0,4 \%$ (v/v) em água e diretamente injetados no sistema de HPLC. Foram injetados $20 \mu \mathrm{L}$ das amostras em uma coluna de fase reversa Ascentis Express C18 (fused core, 4,6 $\times 150 \mathrm{~mm}$, partículas de 2,7 $\mu \mathrm{m}$, Supelco Analytical), termoestatizada a $40{ }^{\circ} \mathrm{C}$. Foram utilizadas as fases móveis: Fase A: Água-Ácido Fórmico (0,4\%), Fase B: Metanol-Ácido Fórmico $(0,4 \%)$. O fluxo foi de 0,28 mL/min. O gradiente de eluição para o solvente B foi: $0 \mathrm{~min}, 0 \%$; $3 \mathrm{~min}, 0 \%$; $25 \mathrm{~min}, 12,5 \%$; $40 \mathrm{~min}, 50 \%$; $45 \mathrm{~min}, 100 \%$; $50 \mathrm{~min}, 100 \%$; $55 \mathrm{~min}, 0,0 \%$. A identificação dos compostos foi baseada no espectro de massas e padrões comerciais (ácido elágico- SigmaAldrich). A quantificação foi realizada a partir de curvas de calibração com detecção a 280,8 nm.

\section{Determinação do conteúdo de glicerina, 2,3-butanodiol e ácidos orgânicos por HPLC}

Para essas análises foi utilizado equipamento de HPLC equipado com bomba quaternária (Jasco, PU-2089 Plus, Quaternary Gradient Pump), injetor automático de amostras (Jasco, AS-1555, Intelligent Sampler) e detector de Índice de Refração (Shodex RI-71). A separação cromatográfica foi realizada por coluna Aminex HPX-87 H (300 X 7,8 mm, $9 \mu$ m de tamanho de partícula). Como fase móvel foi utilizada uma solução de $\mathrm{H}_{2} \mathrm{SO}_{4} 0,008 \mathrm{~N}$ em água ultrapura, de modo isocrático. As seguintes condições cromatográficas foram empregadas: fluxo de $0,6 \mathrm{~mL} / \mathrm{min}$, temperatura de trabalho de $85{ }^{\circ} \mathrm{C}$ e pressão inicial de $49 \mathrm{~atm}$ (5 MPa). Foram utilizados $10 \mu \mathrm{L}$ de amostras do fermentado injetadas diretamente no sistema de HPLC após diluição (1:1) em água. A identificação dos compostos foi realizada com base na comparação dos tempos de retenção dos picos obtidos àqueles obtidos por seus respectivos padrões. A quantificação foi realizada por meio de curvas de calibração utilizando-se padrões autênticos para cada analito. Para os ácidos orgânicos, foi analisada a presença de ácido cítrico, tartárico, succínico, láctico e acético.

\section{Determinação de aminoácidos, aminas biogênicas e íon amônia por HPLC}

A determinação dos aminoácidos e aminas biogênicas foi realizada com base em metodologias descritas previamente (Gómez-Alonso, Hermosín-Gutierrez, \& García-Romero, 2007; Poveda, Molina, \& Gómez-Alonso, 2016). Anteriormente à análise, foram realizadas reações de derivatização por meio da adição, em tubos de ensaio, de 1,75 mL de tampão borato $1 \mathrm{M}$ (pH 9) e $750 \mu \mathrm{L}$ de metanol a $1 \mathrm{~mL}$ das amostras sem nenhuma preparação prévia. Foram adicionados ainda $20 \mu \mathrm{L}$ do padrão interno (L-2- ácido aminoadípico $1 \mathrm{~g} / \mathrm{L}$ ) e $30 \mu \mathrm{L}$ de DEEMM (dietiletoximetilenemalonato). Os tubos foram levados para o banho de ultrason durante 30 min e logo após para estufa a $70{ }^{\circ} \mathrm{C}$ por duas horas, para a completa degradação do excesso de 
DEEMM. A análise por HPLC foi realizada por equipamento Agilent 1200 (Agilent Technologies, Madrid, Espanha), equipado com bomba binária e injetor automático de amostras. A separação cromatográfica foi realizada por coluna Zorbax Eclipse XDB C18 com partículas de $5 \mu \mathrm{m}\left(12,5 \mathrm{~mm}\right.$ x 4,6 mm), termoestatizada a $16{ }^{\circ} \mathrm{C}$. Foram utilizadas duas fases móveis, em gradiente binário de eluição. A fase móvel A ( $25 \mathrm{mM}$ de tampão acetato pH 5,8 com 0,02\% v/v de trinitrogeneto de sódio NaN3) e a fase móvel B (acetronitrilo: metanol 80:20 v/v) seguiram o fluxo de vazão de 0,9 $\mathrm{mL}$ e o seguinte quociente de eluição: zero min (90\% A e 10\% B), $20 \min (90 \%$ A e 10\% B), 30,5 min (83\% A e 17\% B), 33,5 min (83\% A e 17\% B), 65 $\min (60 \%$ A e $40 \%$ B), $73 \min (28 \%$ A e $72 \%$ B), $78 \min (18 \%$ A e $82 \%$ B), $82 \min (0 \%$ A e $100 \%$ B), $85 \min (0 \%$ A e $100 \%$ B). A detecção dos compostos foi realizada por um detector tipo DAD (Agilent), sendo utilizados os comprimentos de onda de $260 \mathrm{~nm}$ para o íon amônia e $280 \mathrm{~nm}$ para os demais compostos. A identificação dos compostos foi realizada com base nos tempos de retenção comparados com os tempos de retenção dos padrões autênticos, sob as mesmas condições de análise. Foram utilizados os padrões para os seguintes aminoácidos: isoleucina, leucina, valina, fenilalanina, metionina, treonina, triptofano, lisina, asparagina, glutamina, alanina, arginina, cisteína, glicina, prolina, serina, tirosina, histidina, aspartato, ornitina e ácido gama-aminobutírico (gaba), aminas biogênicas: putrescina, $\beta$-feniletilamina, histamina, tiramina, triptamina e cadaverina e o íon amônio. A quantificação foi realizada com base no padrão interno.

\section{Resultados e Discussão}

Por meio dos resultados apresentados na caracterização química do fermentado de jabuticaba (Tabela 1) foi notório que a sacarose adicionada ao mosto de fermentação foi completamente hidrolisada pelas leveduras adicionadas ao mosto, originando frutose e glicose, únicos açúcares presentes, dentre os analisados. Esses açúcares redutores e fermentescíveis, somados aos naturalmente presentes na jabuticaba $(0,261 \mathrm{~g} / 100 \mathrm{~g}$ de glicose e $0,388 \mathrm{~g} / 100 \mathrm{~g}$ de frutose e $5,356 \mathrm{~g} / 100 \mathrm{~g}$ de sacarose) foram fermentados pelas leveduras, originando o etanol. A glicose é prontamente fermentada por leveduras da espécie $S$. cerevisiae, bem como outros açúcares, desde que haja mecanismo de transporte da molécula pela membrana plasmática e enzimas capazes de realizar a fermentação. A frutose, isômero da glicose, é rapidamente convertida e metabolizada, já a sacarose é hidrolisada pela enzima invertase, originando uma molécula de frutose e uma de glicose (Vitolo, 2019).

Tabela 1. Caracterização de fermentado alcoólico de jabuticaba produzido de maneira artesanal.

\begin{tabular}{cc}
\hline Parâmetro analisado & Valor obtido \\
\hline Glicose + Frutose $(\mathrm{g} / \mathrm{L})$ & $4,700 \pm 2,207$ \\
Sacarose $(\mathrm{g} / \mathrm{L})$ & n.d. \\
Açúcares totais $(\mathrm{g} / \mathrm{L})$ & $4,700 \pm 2,207$ \\
Etanol $\left({ }^{\circ} \mathrm{GL}\right)$ & $8,797 \pm 0,525$ \\
$\mathrm{pH}$ & $3,128 \pm 0,023$ \\
Compostos fenólicos totais $(\mathrm{mg} / \mathrm{L})$ & $861,574 \pm 84,262$ \\
Capacidade antioxidante $(\mu \mathrm{mol}$ Trolox/L) & $6,854 \pm 0,512$ \\
Antocianinas Totais $(\mathrm{mg} / \mathrm{L})$ & $35,758 \pm 2,922$ \\
Antocianinas Polimerizadas $(\mathrm{mg} / \mathrm{L})$ & $9,394 \pm 0,525$ \\
Taninos $(\mathrm{mg} / \mathrm{L})$ & $15,864 \pm 3,602$ \\
\hline
\end{tabular}

n.d. = valores não detectáveis. Fonte: Autores.

Embora a fermentação tenha ocorrido de forma completa, quando se observou o cessar da atividade microbiana, o açúcar não foi totalmente consumido pela fermentação, restando em média 4,700 g/L de açúcares. O fim da atividade microbiana pode ocorrer devido ao aumento do teor de etanol no meio e redução do pH. Embora a espécie $S$. cerevisiae resista a altas concentrações de etanol (até $18 \%$ v/v), o crescimento do microrganismo pode cessar em concentrações próximas a 10\% (Lin \& Tanaka, 2006). 
O teor de etanol apresentado está coerente com a quantidade de sacarose adicionada na etapa de chaptalização. Sendo considerada o volume líquido inicial de $3 \mathrm{~L}$, para os quais foi adicionado $700 \mathrm{~g}$ de sacarose, sabendo-se, segundo a estequiometria da equação de conversão de glicose à etanol, não necessárias cerca de $180 \mathrm{~g}$ de glicose para a produção de $92 \mathrm{~g}$ de etanol (Schweinberger, Trierweiler, \& Trierweiler, 2019). Assim, $700 \mathrm{~g}$ de sacarose seriam capazes de produzir $376,85 \mathrm{~g}$ de etanol, resultando em um teor alcoólico de $12,56 \%$. No entanto, sabe-se que a conversão de glicose a etanol dificilmente chega a 100\%, uma vez que o etanol não é o único produto da fermentação e que as leveduras também realizam respiração aeróbica durante seu crescimento (Aquarone, Borzani, Schmidell, \& Lima, 2001). Ainda, é notória a presença de açúcar residual, indicando que o substrato não foi inteiramente consumido. $\mathrm{O}$ resultado apresentado está de acordo com a legislação brasileira que preconiza que fermentados alcoólicos de frutas devem conter de 4 a 14\% (v/v) de etanol (Brasil, 2009).

Fermentados alcoólicos são bebidas com baixos valores de pH. Fato relacionado ao fruto e aos ácidos orgânicos decorrentes do processo fermentativo. Em um trabalho anterior com fermentado alcoólico de jabuticaba, foi encontrado valores de pH entre 3,16 e 3,80 (Silva, Faria, Tonon, Pinto, \& Tensol, 2008), valores comparáveis ao encontrados neste trabalho.

Os compostos fenólicos são uma classe de compostos presentes em diversos tipos de bebidas fermentadas e desejáveis, devido às diversas alegações de seus benefícios à saúde (Arranz et al., 2012). Naturalmente presentes na jabuticaba, esses compostos são facilmente extraídos, sobretudo das cascas e sementes (Neves, Stringheta, Gómez-Alonso, \& HermosínGutiérrez, 2018) pelo meio hidroalcoólico do mosto fermentativo (Veggi, Santos, \& Meireles, 2011). Da mesma forma que o meio é capaz de extrair os compostos, uma vez em solução esses são facilmente degradados, devido à sua alta instabilidade à luz, pH, presença de açúcares, etanol, dentre outros, podendo também sofrer complexações (Moldovan, David, Chişbora \& Cimpoiu, 2012; Tseng, Chang \& Wu, 2006; Tsukui, Murakami, Shiina \& Hayashi, 2002). A polimerização das antocianinas é um fenômeno comum em produtos processados, nos quais estes pigmentos encontram-se mais livres no meio, aptas a se condensarem com outras antocianinas e /ou flava-3-ols. A polimerização resulta em mudanças na cor e sabor das bebidas, além de levar à estabilidade do pigmento (He et al., 2012). Nos resultados apresentados, houve complexação de 26,27\% das antocianinas.

A capacidade antioxidante está diretamente relacionada ao conteúdo de compostos fenólicos de um produto. Dessa forma, espera-se que esta característica seja diretamente proporcional à concentração de compostos fenólicos. Mas isso nem sempre é observado na prática, pois além da concentração, o tipo de composto fenólico é decisivo para definir a capacidade antioxidante de um produto (Zhang \& Tsao, 2016). A capacidade antioxidante encontrada para o fermentado alcoólico de jabuticaba foi inferior à encontrada em 31 vinhos da Itália e da República da Macedônia (0,35 a 6,52 mmol Trolox/L), utilizando a mesma metodologia (Ricci, Teslic, Petropolus, Parpinello, \& Versari, 2019).

Taninos são polifenóis naturalmente presentes em plantas. Possuem variados tipos de estruturas químicas, podendo ser classificados em taninos condensados e hidrolisáveis. Além de apresentar propriedades antioxidantes, os taninos são reconhecidos por estabilizar a coloração de vinhos tintos, formando estruturas complexas com as antocianinas e contribuir para o corpo, adstringência da bebida (Motta, Guaita, Cassino, \& Bosso, 2020). A título de comparação, o fermentado de jabuticaba apresentou concentrações de taninos superiores aos encontrados em vinhos de uva Tannat (1,4 a $26 \mathrm{~g} / \mathrm{L}$ ) (Rizzon \& Miele, 2004) e Cabernet Franc (0,89 a 1,79 g/L) (Manfroi, Miele, Rizzon, \& Barradas, 2006).

A tonalidade, medida que representa o desenvolvimento da coloração marrom-alaranjada, é um parâmetro analisado em vinhos e um indicativo da maturação de uma bebida. Ao longo do envelhecimento, há a tendência à polimerização das antocianinas, que sofrem efeito batocrômico e passam a adquirir uma coloração mais laranjada em detrimento ao vermelho intenso. Dessa forma, vinhos jovens possuem tonalidade entre 0,5 e 0,7 enquanto vinhos amadurecidos são encontrados de 1,2 a 1,3 (Ribéreau-Gayon et al., 2002). Os resultados obtidos para esse parâmetro (Tabela 2) são coerentes com a baixa complexação das antocianinas apresentadas, podendo ser comparado a "vinhos jovens". 
Tabela 2. Intensidade de cor, tonalidade e composição da cor de fermentado alcoólico de jabuticaba obtido de maneira artesanal.

\begin{tabular}{ccc}
\hline \multicolumn{2}{c}{ Parâmetro analisado } & Valor obtido \\
\hline \multicolumn{2}{c}{ Intensidade de cor } & $0,218 \pm 0,010$ \\
Tonalidade & $0,729 \pm 0,034$ \\
& $420 \mathrm{~nm}$ & $38,341 \pm 1,027$ \\
Composição da cor & $520 \mathrm{~nm}$ & $52,643 \pm 1,076$ \\
& $620 \mathrm{~nm}$ & $9,015 \pm 0,305$ \\
\hline
\end{tabular}

Fonte: Autores.

Intensidade de cor é uma medida que representa a soma das absorbâncias nos comprimentos de onda de 420, 520 e $620 \mathrm{~nm}$ e é uma característica qualitativa em vinhos, que está relacionada ao tipo de uva utilizada (Ribéreau-Gayon et al., 2002). Para fermentado alcoólico de jabuticaba, essa pode ser uma medida realizada no intuito de caracterizar as bebidas e fornecer um padrão para comercialização, criando assim, uma identidade a ela. Os resultados apresentados caracterizam o fermentado com coloração menos intensa do que em vinhos jovens, que podem variar de 2,63 a 3,14 para uvas das variedades Cornivo e Corvinone (Celotti et al., 2020) e até 9,35 a 9,64 em uvas da variedade Syrah (Silva, Santos, Nogueira, Barros, \& Biasoto, 2020). Fato resultante da menor concentração de antocianinas nas bebidas de jabuticaba, quando comparada a vinhos. Os resultados mostraram também que a maior contribuição da coloração é no comprimento de onda de $520 \mathrm{~nm}$, caracterizando tons vermelhos, seguido por $420 \mathrm{~nm}$, que caracterizam tons mais amarelados e pode ser um resultado da polimerização das antocianinas. O comprimento de onda de $620 \mathrm{~nm}$, que representa os componentes de azul em vinhos jovens, obteve a menor absorbância.

No fermentado de jabuticaba foram identificadas somente quatro das cinco estruturas de antocianinas presentes nas cascas da jabuticaba sabará in natura, sendo elas delfinidina-3-glicosídio (dp-3-glc), cianidina-3-glicosidio (cy-3-glc), pelargonidina-3-glicosídio (pg-3-glc), peonidina-3-glicosídio (pn-3-glc) e cianidina-3-coumarilglicosídio (cy-3-cmglc) (Neves et al., 2021). O teor de cy-3-cmglc nas cascas da jabuticaba sabará é pequeno em relação às demais antocianinas, não sendo suficiente para a manutenção desta, em quantidades detectáveis, após o processo de obtenção do fermentado. Dentre as antocianinas presentes destacam-se a cy-3-glicosídeo e a dp-3-glicosídeo, presentes majoritariamente nas bebidas (Tabela 3). Esse fato é justificável pela maior concentração dessas duas antocianinas nas cascas dos frutos. Nota-se ainda a presença de pg-3-glicosídeo e pn-3-glicosídeo, presentes em concentrações muito inferiores, a exemplo do ocorrido nas cascas das jabuticabas.

Tabela 3. Concentração de antocianinas monoméricas em fermentado alcoólico de jabuticaba.

\begin{tabular}{cc}
\hline Parâmetro analisado & Valor obtido \\
\hline Antocianinas & (mg equivalentes de cianidina-3-glicosídeo/L) \\
dp-3-glc & $2,649 \pm 0,428$ \\
cy-3-glc & $18,277 \pm 2,785$ \\
pn-3-glc & $0,080 \pm 0,027$ \\
pg-3-glc & $0,137 \pm 0,005$ \\
\hline Ácido elágico $(\mathrm{mg} / \mathrm{L}$ & $26,894 \pm 5,594$ \\
\hline
\end{tabular}

dp-3-glc = delfinidina-3-glicosídeo; cy-3-glc= cianidina-3-glicosídeo; pn-3-glc= peonidina-3-glicosídeo; pg-3-glc= pelagornidina-3glicosídeo. Fonte: Autores.

O ácido elágico é um antioxidante abundante na natureza. Quimicamente, é um derivado dimérico do ácido gálico, pertencente ao grupo dos polifenóis dilipídicos (Chen et al., 2019). Os resultados encontrados no fermentado de jabuticaba são superiores aos encontrados em 35 amostras de vinhos brasileiros e argentinos (1,37 a 8,07 mg/L (Carneiro et al., 2020), indicando que o meio fermentativo foi eficiente na extração da concentração desse composto presente na jabuticaba, tornando 
esse tipo de bebida uma importante fonte de ácido elágico.

Dentre os ácidos orgânicos analisados, o ácido cítrico foi o majoritário no fermentado alcoólico (Tabela 4). Esse ácido é naturalmente presente nas jabuticabas (Oliveira, Silva, \& Scarpare Filho, 2020) tendo possivelmente migrado do fruto para o meio fermentativo. Embora o ácido succínico seja encontrado em vinhos em consequência da fermentação alcoólica, como resultado do metabolismo das leveduras, ele pode ocorrer naturalmente em algumas frutas, como é o caso da jabuticaba, que já teve esse ácido relatado como o segundo mais abundante no fruto, que contém também os ácidos cítrico, málico, oxálico e acético (Lima, Corrêa, Dantas-Barros, Nelson \& Amorim, 2011). Além dos ácidos presentes naturalmente na jabuticaba, o fermentado apresentou ácidos originários em decorrência do processo fermentativo (lático e acético) além de 2,3-butanodiol e glicerina.

Tabela 4. Concentração de ácidos orgânicos, 2,3-butanodiol e glicerina em fermentado alcoólico de jabuticaba.

\begin{tabular}{cc}
\hline Parâmetro analisado & Valor obtido $(\mathbf{g} / \mathbf{L})$ \\
\hline Ácido Málico & $0,670 \pm 0,040$ \\
Ácido Cítrico & $2,777 \pm 0,317$ \\
Ácido Succínico & $1,363 \pm 0,155$ \\
Ácido Láctico & $0,070 \pm 0,010$ \\
Ácido Acético & $0,080 \pm 0,036$ \\
Total & $\mathbf{4 , 9 6 0 \pm 0 , 5 2 6}$ \\
\hline 2,3 butanodiol & $0,210 \pm 0,036$ \\
Glicerina & $7,720 \pm 1,117$ \\
\hline
\end{tabular}

Fonte: Autores.

Em relação à concentração total de ácidos orgânicos, o fermentado está dentro do intervalo de 4,9 a 10,3 g/L para os mesmos ácidos estudados, encontrados em 31 vinhos de diferentes uvas e safras (Zeravik et al., 2016), embora esteja próximo dos valores mais baixos. O teor de ácido málico encontrado está próximo ao valor reportado anteriormente para fermentado alcoólico de jabuticaba $(0,62 \pm 0,03 \mathrm{~g} / \mathrm{L})$ (Duarte et al., 2010), no entanto o valor encontrado para a concentração de ácido succínico no mesmo trabalho $(5,11 \pm 0,19 \mathrm{~g} / \mathrm{L})$ é superior aos valores observados neste.

O ácido acético é o principal ácido volátil presentes nos vinhos. É produzido principalmente por bactérias acéticas que são consideradas contaminantes em vinhos, pois seus metabólitos resultam em características sensoriais desagradáveis (Rodríguez-Gamboa, Albarracin, Silva, Lima, \& Ferreira, 2019). Valores acima de 0,4-0,5 g/L são indesejáveis em vinhos secos (Longin, Guilloux-Benatier \& Alexandre, 2016). A legislação brasileira para fermentados alcoólicos de frutas (Brasil 2009) não estabelece padrões para a concentração de ácido acético nas bebidas. No entanto, tendo-se como referência os limites aceitáveis para vinhos, o conteúdo de ácido acético encontrado no fermentado de jabuticaba está dentro do valor desejável. Esse fato sugere que, mesmo em se tratando de uma produção artesanal, onde não há controle das variáveis do processo de fermentação, as medidas adotadas para a elaboração foram suficientes para evitar a contaminação dessas bebidas por bactérias acéticas, até o momento da análise. Dado anterior reporta a concentração de ácido acético em fermentado de jabuticaba $(0,78 \pm 0,15 \mathrm{~g} / \mathrm{L})$ próximo aos valores encontrados (Duarte et al., 2010).

A concentração de 2,3-butanodiol está entre os valores de 0,149 a 6,509 g/100g reportados na literatura para 33 vinhos varietais (Dourtoglou, Antonopoulos, Dourtoglo, \& Lalas, 2014). Estudos indicam que essa substância é produzida em vinhos com elevados teores de acidez (Celińska \& Grajek, 2009). Dessa forma, a baixa concentração de 2,3-butanodiol no fermentado de jabuticaba pode ter sido influenciada pela baixa concentração relativa de ácidos orgânicos nessas bebidas. A concentração de glicerina também está dentro do esperado para bebidas desse tipo, sendo que em vinhos são encontrados valores entre 5 e 20 g/L (Ribéreau-Gayon et al., 2002). Esses valores também estão próximos ao encontrado anteriormente para fermentado alcoólico de jabuticaba (7,56 $\pm 0,38 \mathrm{~g} / \mathrm{L})$ (Duarte et al., 2010). 
Durante a fermentação alcoólica para a obtenção de vinhos e demais bebidas, observa-se a relação direta entre os níveis de aminoácidos nos mostos e seu consumo durante a primeira metade da fermentação, sendo eles utilizados como fonte de nitrogênio pelos microrganismos (Bouzas-Cid, Falqué, Orriols, \& Mirás-Avalos, 2018;Carrera, Ruiz-rodríguez, Palma, \& Barroso, 2015). Ao decorrer da fermentação, espera-se o aumento da concentração de aminoácidos devido à síntese e a liberação após a morte e lise das células (Cerrillo et al., 2015). Além disso, o perfil de aminoácidos dos mostos irá influenciar a qualidade final do vinho devido às transformações que aminoácidos sofrem durante o processo de fermentação, produzindo compostos voláteis, como álcoois superiores, ácidos graxos voláteis e etil ésteres que definem o aroma de vinho (Bouzas-Cid et al., 2018).

Dentre os aminoácidos investigados, estavam presentes no fermentado somente a alanina, metionina, prolina e valina (Tabela 5), sendo a concentração destes inferiores ao normalmente encontrado em vinhos. O aminoácido majoritário foi a alanina, que é considerada uma das fontes de nitrogênio mais prontamente disponíveis para as leveduras (Gutiérrez-Gamboa et al., 2018). A prolina é sintetizada por leveduras da S. cerevisiae a partir do L-glutamato. Essa conversão é vantajosa uma vez que a prolina atua como um osmoprotetor, protegendo as células do estresse oxidativo e conferindo uma maior tolerância à presença de etanol durante a fermentação alcoólica (Takagi, Takaoka, Kawaguchi \& Kubo, 2005).

Tabela 5. Concentração dos aminoácidos, íon amônio e aminas biogênicas identificadas em fermentado alcoólico de jabuticaba.

\begin{tabular}{ccc}
\hline \multicolumn{2}{c}{ Parâmetro analisado } & Valor obtido (mg/L) \\
\hline & Alanina & $75,907 \pm 16,464$ \\
Aminoácidos & Metionina & $4,528 \pm 0,614$ \\
& Prolina & $2,269 \pm 0,753$ \\
& Valina & $15,947 \pm 7,280$ \\
$\mathrm{NH}_{4}{ }^{+}$ & & $2,738 \pm 0,641$ \\
Aminas biogênicas & $\beta$-feniletilamina & $4,466 \pm 1,803$ \\
& Putrescina & $26,401 \pm 5,938$ \\
\hline
\end{tabular}

Fonte: Autores.

Assim com os aminoácidos, o íon amônio é essencial para crescimento de leveduras durante a fermentação alcoólica e bactérias lácticas, durante a fermentação malolática. A concentração de $\mathrm{NH}_{4}{ }^{+}$nos fermentados de jabuticaba está entre os valores de 1,29 a 12,81 mg/L encontrados em vinhos da região de Castilla La Mancha (Gómez-Alonso et al., 2007) e 0,29 a $96,24 \mathrm{mg} / \mathrm{L}$ em vinhos de diferentes frutas (Ouyang et al., 2017).

Dentre as aminas biogênicas investigadas, somente foram encontradas no fermentado a $\beta$-feniletilamina e putrescina. A histamina, tiramina e cadaverina, que são comuns em alimentos e bebidas não foram detectadas. Produto da fermentação e armazenamento, as aminas biogênicas podem ser toxicas em altas concentrações. A presença de diversos tipos de aminas pode potencializar a toxidez. Como o caso da histamina que possui efeito tóxico em concentrações acima de 500 ppm, no entanto, sozinha pode não causar efeito tóxico em baixas concentrações, mas na presença de outras aminas, tais como putrescina e cadaverina, em concentrações cinco vezes superiores a da histamina, potencializa a sua toxidez (Naila, Flint, Fletcher, Bremer \& Meerdink, 2010). Não é recomendável concentrações acima de $50 \mathrm{mg} / \mathrm{L}$ de aminas biogênicas em vinhos tintos. Os valores encontrados nesse trabalho estão abaixo do limite de toxidez, atestando a segurança do produto para o consumo, mesmo que artesanal.

\section{Conclusão}

Na qualidade de bebida artesanal e com baixo valor agregado, o fermentado alcoólico de jabuticaba é pouco estudado, não havendo nenhum tipo de padrão de qualidade. Assim, trabalhos de caracterização química dessa bebida tornam-se interessantes objetos para futuras comparações. 
A caracterização da bebida mostrou-se coerente com trabalhos anteriores e em conformidade com a legislação brasileira para essa classe de produto. A caracterização da composição fenólica mostrou um teor de ácido elágico acima do normalmente encontrado para vinhos, sendo um fator interessante do ponto de vista da capacidade antioxidante da bebida, fator muito valorizado em vinhos.

Os resultados mostraram a boa qualidade sanitária da bebida, com indicativos de ausência de contaminação microbiana dado o baixo teor de ácido acético e aminas biogênicas, mostrando a possibilidade de obtenção de produtos de qualidade, mesmo com o baixo emprego de tecnologia.

\section{Agradecimentos}

Ao CNPq (Conselho Nacional de Desenvolvimento Científico e Tecnológico) pela concessão de bolsa de doutorado Sanduíche à N.A. Neves por meio do programa Ciência sem Fronteiras e à CAPES (Coordenação de Aperfeiçoamento de Pessoal de Nível Superior) pela concessão de bolsa de Doutorado.

Ao Dr. Isidro Hermosín-Gutiérrez (in memoriam) pela valiosa contribuição a esse trabalho.

\section{Referências}

Aquarone, E., Borzani, W., Schmidell, W., \& Lima, U. A. (2001). Biotecnologia Industrial, Volume 4, Biotecnologia na Produção de Alimentos, . (Ed. Edgard Blücher Ltda., Org.) (1a ed.). São Paulo.

Arranz, S., Chiva-Blanch, G., Valderas-Martínez, P., Medina-Remón, A., Lamuela-Raventós, R. M., \& Estruch, R. (2012). Wine, Beer, Alcohol and Polyphenols on Cardiovascular Disease and Cancer. Nutrients, 4(12), 759-781.

Bouzas-Cid, Y., Falqué, E., Orriols, I., \& Mirás-Avalos, J. M. (2018). Effects of irrigation over three years on the amino acid composition of Treixadura (Vitis vinifera L.) musts and wines, and on the aromatic composition and sensory profiles of its wines. Food Chemistry, 240, 707-716.

Brand-Williams, W., Cuvelier, M. E., \& Berset, C. (1995). Use of a free radical method to evaluate antioxidant activity. LWT - Food Science and Technology, $28(1), 25-30$.

Carneiro, C. N., Gomez, F. J. V., Spisso, A., Silva, M. F., Azcarate, S. M., \& Dias, F. de S. (2020). Geographical characterization of South America wines based on their phenolic and melatonin composition: An exploratory analysis. Microchemical Journal, 158, 105240.

Carrera, C., Ruiz-Rodríguez, A., Palma, M., \& Barroso, C. G. (2015). Ultrasonics Sonochemistry Ultrasound-assisted extraction of amino acids from grapes. Ultrasonics Sonochemistry, 22, 499-505.

Celińska, E., \& Grajek, W. (2009). Biotechnological production of 2,3-butanediol—Current state and prospects. Biotechnology Advances, 27(6), 715-725.

Celotti, E., Stante, S., Ferraretto, P., Román, T., Nicolini, G., \& Natolino, A. (2020). High Power Ultrasound Treatments of Red Young Wines: Effect on Anthocyanins and Phenolic Stability Indices. Foods, 9(10), 1344.

Cerrillo, I., Fernández-Pachón, M. S., Collado-González, J., Escudero-López, B., Berná, G., Herrero-Martín, G., Gil-Izquierdo, A. (2015). Effect of Fermentation and Subsequent Pasteurization Processes on Amino Acids Composition of Orange Juice. Plant Foods for Human Nutrition, 70(2), 153-159.

Chen, R., Li, J., Yang, Z., Gao, F., Qi, P., Li, X., \& Zhang, J. (2019). Determination of Ellagic Acid in Wine by Solid-Phase Extraction-Ultra-High Performance Liquid Chromatography-Tandem Mass Spectrometry. Food Analytical Methods, 12(5), 1103-1110.

Dourtoglou, V., Antonopoulos, A., Dourtoglou, T., \& Lalas, S. (2014). Discrimination of varietal wines according to their volatiles. Food Chemistry, 159, $181-187$.

Duarte, W. F., Dias, D. R., Oliveira, J. M., Teixeira, J. A., Almeida e Silva, J. B., \& Schwan, R. F. (2010). Characterization of different fruit wines made from cacao, cupuassu, gabiroba, jaboticaba and umbu. LWT - Food Science and Technology, 43(10), 1564-1572.

Embrapa. (2010). Metodologia para análise de vinho. (L. A. Rizzon, Org.): Embrapa. 120p.

Glories, Y. (1984). La couleur des vins rouges. 2ème partie mesure, origine et interpretation. Connaissance de la Vigne et du Vin, 18, $253-271$.

Gómez-Alonso, S., Hermosín-Gutierrez, I., \& García-Romero, E. (2007). Simultaneous HPLC Analysis of Biogenic Amines , Amino Acids , and Ammonium Ion as Aminoenone Derivatives in Wine and Beer Samples. Journal of Agricultural and Food Chemistry, 55, 608-613.

Gurak, P. D., Bona, G. S., Tessaro, I. C., \& Marczak, L. D. F. (2014). Jaboticaba pomace powder obtained as a co-product of juice extraction: A comparative study of powder obtained from peel and whole fruit. Food Research International, 62, 786-792.

Gutiérrez-Gamboa, G., Carrasco-Quiroz, M., Martínez-Gil, A. M., Pérez-Álvarez, E. P., Garde-Cerdán, T., \& Moreno-Simunovic, Y. (2018). Grape and wine amino acid composition from Carignan noir grapevines growing under rainfed conditions in the Maule Valley, Chile: Effects of location and rootstock. Food Research International, 105, 344-352. 
He, F., Liang, N. N., Mu, L., Pan, Q. H., Wang, J., Reeves, M. J., \& Duan, C. Q. (2012). Anthocyanins and their variation in red wines II. Anthocyanin derived pigments and their color evolution. Molecules, 17(2), 1483-1519.

Inada, K. O. P., Oliveira, A. A., Revorêdo, T. B., Martins, A. B. N., Lacerda, E. C. Q., Freire, A. S., Monteiro, M. C. (2015). Screening of the chemical composition and occurring antioxidants in jabuticaba (Myrciaria jaboticaba) and jussara (Euterpe edulis) fruits and their fractions. Journal of Functional Foods, 17, 422-433.

Leite-legatti, A. V., Giovana, Â., Romanelli, N., Dragano, V., Castro, A., Gomes, L., \& Júnior, M. (2012). Jaboticaba peel : Antioxidant compounds , antiproliferative and antimutagenic activities. Food Research International, 49, 596-603.

Lima, A. de J. B., Corrêa, A. D., Dantas-Barros, A. M., Nelson, D. L., \& Amorim, A. C. L. (2011). Sugars, Organic Acids, Minerals and Lipids in Jabuticaba. Revista Brasileira de Fruticultura, 33(2), 540-550.

Lin, Y., \& Tanaka, S. (2006). Ethanol fermentation from biomass resources: current state and prospects. Appl Microbiol Biotechnol, 69, 627-642.

Longin, C., Guilloux-Benatier, M., \& Alexandre, H. (2016). Design and Performance Testing of a DNA Extraction Assay for Sensitive and Reliable Quantification of Acetic Acid Bacteria Directly in Red Wine Using Real Time PCR. Frontiers in Microbiology, 7, 831.

Manfroi, L., Miele, A., Rizzon, L. A., \& Barradas, C. I. N. (2006). Composição físico-química do vinho Cabernet Franc proveniente de videiras conduzidas no sistema lira aberta. Ciência e Tecnologia de Alimentos, 26(2), 290-296.

Ministério da Agricultura, Pecuária e Abastecimento (2009). Decreto nº.871 de 4 de junho de 2009. Regulamenta a Lei nº.918, de 14 de julho de 1994 , que dispõe sobre a padronização, a classificação, o registro, a inspeção, a produção e a fiscaliz.

Moldovan, B., David, L., Chişbora, C., \& Cimpoiu, C. (2012). Degradation Kinetics of Anthocyanins from European Cranberrybush (Viburnum opulus L.) Fruit Extracts. Effects of Temperature, pH and Storage Solvent. Molecules, 17, 11655-11666.

Motta, S., Guaita, M., Cassino, C., \& Bosso, A. (2020). Relationship between polyphenolic content, antioxidant properties and oxygen consumption rate of different tannins in a model wine solution. Food Chemistry, 313, 126045.

Naila, A., Flint, S., Fletcher, G., Bremer, P., \& Meerdink, G. (2010). Control of biogenic amines in food - existing and emerging approaches. Journal of Food Science, 75(7), 139-150.

Neves, N. A., Fernandes, L. A. C., Valente, M. E. R., De Barros, F. A. R., \& Stringheta, P. C. (2020). Estudo das características da produção, comercialização e qualidade de produtos derivados de jabuticaba no município de Sabará-Minas Gerais, Brasil. Revista ELO - Diálogos em Extensão, 9, 1-11.

Neves, N. A., Stringheta, P. C., Gómez-Alonso, S., \& Hermosín-Gutiérrez, I. (2018). Flavonols and ellagic acid derivatives in peels of different species of jabuticaba (Plinia spp.) identified by HPLC-DAD-ESI/MSn. Food Chemistry, 252(December 2017), 61-71.

Neves, N. de A., Stringheta, P. C., Silva, I. F. da, García-Romero, E., Gómez-Alonso, S., \& Hermosín-Gutiérrez, I. (2021). Identification and quantification of phenolic composition from different species of Jabuticaba (Plinia spp.) by HPLC-DAD-ESI/MSn. Food Chemistry, 129605.

OIV-International organization of vine and wine. (2013). Compendium of International Methods of Wine and Must Analysis. Paris: OIV.

Oliveira, G. P., Silva, S. R. da, \& Scarpare Filho, J. A. (2020). Curva de maturação da jabuticaba 'Sabará'. Research, Society and Development, 9(7), e296974212.

Ough, C. S., \& Amerine, A. (1988). Methods Analysis of Musts and Wines. Wiley.

Ouyang, X., Wang, S., Yuan, G., Liu, Y., Gu, P., Zhang, B., \& Zhu, B. (2017). Comparison of amino acids, biogenic amines and ammonium ion of wines made of different types of fruits. International Journal of Food Science \& Technology, 52(2), 448-456.

Poveda, J. M., Molina, G. M., \& Gómez-Alonso, S. (2016). Variability of biogenic amine and free amino acid concentrations in regionally produced goat milk cheeses. Journal of Food Composition and Analysis, 51, 85-92.

Rebello, L. P. G., Lago-Vanzela, E. S., Barcia, M. T., Ramos, A. M., Stringheta, P. C., Da-Silva, R., \& Hermosín-Gutiérrez, I. (2013). Phenolic composition of the berry parts of hybrid grape cultivar BRS Violeta (BRS Rubea×IAC 1398-21) using HPLC-DAD-ESI-MS/MS. Food Research International, 54(1), 354366.

Ribéreau-Gayon, P., Glories, Y., Maujean, A., \& Duboudieu, D. (2002). Handbook of enology. Volume 2. The Chemistry of wine, stabilization and treatments.

Ribéreau-Gayon, P., \& Stonestreet, E. (1965). Le dosage des anthocyanes dans les vins rouges. Bulletin de la Société de Chimie, 9, $2649-2652$.

Ricci, A., Teslic, N., Petropolus, V.-I., Parpinello, G. P., \& Versari, A. (2019). Fast Analysis of Total Polyphenol Content and Antioxidant Activity in Wines and Oenological Tannins Using a Flow Injection System with Tandem Diode Array and Electrochemical Detections. Food Analytical Methods, 12(2), 347354.

Rizzon, L. A., \& Miele, A. (2004). Avaliação da cv. Tannat para elaboração de vinho tinto. Ciência e Tecnologia de Alimentos, 24(2), $223-229$.

Rodriguez Gamboa, J. C., Albarracin E, E. S., da Silva, A. J., L. de Andrade Lima, L., \& E. Ferreira, T. A. (2019). Wine quality rapid detection using a compact electronic nose system: Application focused on spoilage thresholds by acetic acid. $L W T, 108,377-384$.

Santiago, Â. M., Conrado, L. de S., Almeida, R. L. J., Santos, N. C., Muniz, C. E. de S., Galdino, P. O., \& Mota, M. M. de A. (2021). Valorização do resíduo da casca de jabuticaba (Myrciaria cauliflora) para produção da exo-poligalacturonase com Aspergillus niger CCT 0916. Research, Society and Development, 10(1), e13810111592. 
Schweinberger, C. M., Trierweiler, J. O., \& Trierweiler, L. F. (2019). A Simple equation for total reducind sugars (TRS) estimation on sweet potato and ethanol yield potential. Brazilian Journal of Chemical Engineering, 36(1), 33-41.

Silva, P. H. A. da., Faria, F. C. de., Tonon, B., Pinto, S. J. D. M., \& Tensol, V. (2008). Avaliação da composição química de fermentados alcoólicos de jabuticaba (Myrciaria jabuticaba). Quimica Nova, 31(3), 595-600.

Silva, I. S., Santos, R. G. de B., Nogueira, E. T., Barros, A. P. A., \& Biasoto, A. C. T. (2020). Influência do uso de chip de carvalho francês na composição físico-química e colorimétrica de vinho tinto da cultivar Syrah. Research, Society and Development, 9(12), e37491211111.

Takagi, H., Takaoka, M., Kawaguchi, A., \& Kubo, Y. (2005). Effect of L-Proline on sake brewing and ethanol stress in Saccharomyces cerevisiae. Applied and Environmental Microbiology, 71(12), 8656-8662.

Tseng, K.-G., Chang, H.-M., \& Wu, J. S.-B. (2006). Degradation kinetics of anthocyanin in ethanolic solutions. Journal of Food Processing and Preservation, $30,503-514$.

Tsukui, A., Murakami, T., Shiina, R., \& Hayashi, K. (2002). Effect of Alcoholic Fermentation on the Stability of Purple Sweet Potato Anthocyanins. Food science and technology research, 8(1), 4-7.

Veggi, P. C., Santos, D. T., \& Meireles, M. A. a. (2011). Anthocyanin extraction from Jabuticaba (Myrciaria cauliflora) skins by different techniques: economic evaluation. Procedia Food Science, 1(Icef 11), 1725-1731.

Vitolo, M. (2019). Invertase activity of intact Saccharomyces cerevisiae cells cultured in sugarcane molasses by batch fermentation process. World Journal of Pharmacy and Pharmaceutical Sciences, 8(3), 126-137.

Wu, S., Long, C., \& Kennelly, E. J. (2013). Phytochemistry and health benefits of jaboticaba, an emerging fruit crop from Brazil. Food Research International, 54, 148-159.

Zeravik, J., Fohlerova, Z., Milovanovic, M., Kubesa, O., Zeisbergerova, M., Lacina, K., \& Skladal, P. (2016). Various instrumental approaches for determination of organic acids in wines. Food Chemistry, 194, 432-440.

Zhang, H., \& Tsao, R. (2016). Dietary polyphenols, oxidative stress and antioxidant and anti-inflammatory effects. Current Opinion in Food Science, 8, 3342. 